\title{
Comparing survival, tacrolimus trough level, prevalence of biliary stenosis and studying for possible early detection of biliary stenosis in liver transplant recipients at First Central Hospital of Mongolia and various high-volume foreign centers
}

\author{
Anar Ganbold ${ }^{1}$, Bayarmaa Ochirkhuree ${ }^{1}$, Bat-Ireedui Badarch² ${ }^{2}$ Batsaikhan Batsuuri ${ }^{2}$, Ganzorig Batjargal ${ }^{3}$, \\ Amgalan Luvsandorj ${ }^{3}$, Erdene Sandag $^{3}$, Erdenebileg Bavuujav ${ }^{3}$, Chuluunbaatar Donkhim $^{4}$, Sergelen Orgoi ${ }^{3}$
}

\footnotetext{
${ }^{1}$ Department of Gastroenterology, First Central Hospital of Mongolia, Ulaanbaatar, Mongolia

${ }^{2}$ Department of Department of Transplantation, First Central Hospital of Mongolia, Ulaanbaatar, Mongolia

${ }^{3}$ Department of Department of Surgery, First Central Hospital of Mongolia, Ulaanbaatar, Mongolia

${ }^{4}$ Department of Anesthesia, First Central Hospital of Mongolia, Ulaanbaatar, Mongolia
}

Background: Since 2015, First Central Hospital of Mongolia independently transplanted 62 living donor liver grafts in 60 adult and pediatric patients (domestic-group). Separately, First Central Hospital of Mongolia follows-up on 243 Mongolian post-transplant patients from foreign clinics (foreign-group).

Methods: In this study, we compared these two groups for 1-year graft and patient survival, prevalence of biliary stenosis (BS), tacrolimus oral dose and trough levels, transaminase and creatinine levels. Alkaline phosphatase (ALP) of patients with radiologically diagnosed and endoscopically treated BS were compared to non-stenotic patients from 1 to 12 months postoperative in a bid to correlate its change with BS later on.

Results: One-year recipient and graft survival in the domestic-group was $90 \%$ and $87 \%$, respectively. Prevalence of BS in this group was $28.5 \%$, while in the foreign-group it was $17.2 \%$. ALP in the BS group tended to increase from the second month on and reached statistical significance on 3rd month compared (215.7 u/L; standard error of the mean [SEM], \pm 36.76$)$ to control group (108.7 u/L, SEM $\pm 19.85, P=0.039$ ). Trough tacrolimus level at 3rd year in domestic-group was $6.3 \mathrm{ng} / \mathrm{mL}$ (standard deviation [SD], \pm 2.9 ), while in foreign-group it was $3.9(\mathrm{SD} \pm 1.6) \mathrm{ng} / \mathrm{mL}$. Daily oral tacrolimus level at $3 \mathrm{rd}$ year in the domestic-groups was $3.8 \mathrm{mg} /$ day, while in the foreign-group it was $2.4 \mathrm{mg} /$ day.

Conclusions: There was no significant difference in transaminases and creatinine between the groups. Survival of recipients depend not only the surgical technique, but also on quality of follow-up. Therefore, for the domestic-group tighter adherence to scheduled check-ups and better collection of information is required. BS that would require endoscopic intervention is likely to manifest itself with a 2xULN change in ALP as early as 3rd month. Physician-controlled immunosuppressant minimization is not only safe but also is required to avoid long-term side-effects.

Corresponding author: Anar Ganbold

E-mail: g.anar@fchm.edu.mn

(c) The Korean Society for Transplantation

This is an Open Access article distributed under the terms of the Creative Commons Attribution Non-Commercial License (http://creativecommons.org/licenses/by-nc/4.0/) which permits unrestricted non-commercial use, distribution, and reproduction in any medium, provided the original work is properly cited. 